\title{
Auricular Acupressure for Adverse Events Following Immunization Related To COVID-19 Vaccine Injection: Study Protocol for a Multicenter, Three- Arm, Blinded Randomized Controlled Trial
}

\section{Qinwei Fu}

Chengdu University of Traditional Chinese Medicine

Hui Xie

Chengdu University of Traditional Chinese Medicine

\section{Li Zhou}

Chengdu University of Traditional Chinese Medicine Xinrong Li

Chengdu University of Traditional Chinese Medicine

Yang Liu

Chengdu University of Traditional Chinese Medicine

Min Liu

Du Jiang Yan Medical Center

Chaoyu Wang

Chengdu University of Traditional Chinese Medicine

Xiaocen Wang

Chengdu University of Traditional Chinese Medicine

Zhiqiao Wang

Chengdu University of Traditional Chinese Medicine

\section{Jinfan Tang}

Chengdu University of Traditional Chinese Medicine

\section{Huan Xiao}

Chengdu University of Traditional Chinese Medicine

\section{Zhiyong Xiao}

Chengdu University of Traditional Chinese Medicine Jing Zhou

Chengdu University of Traditional Chinese Medicine Chengzhi Feng

Chengdu University of Traditional Chinese Medicine

\section{Li Wang}

Chengdu University of Traditional Chinese Medicine 


\section{Zhimin Ao}

Chengdu University of Traditional Chinese Medicine

\section{Xi Chen}

Chengdu University of Traditional Chinese Medicine

\section{Chang Su}

Chengdu University of Traditional Chinese Medicine

\section{Xuanyu Wu}

Chengdu University of Traditional Chinese Medicine

\section{Maolan Zhao}

Chengdu University of Traditional Chinese Medicine

\section{Sihan Hu}

Chengdu University of Traditional Chinese Medicine

\section{Hanwen Lin}

Chengdu University of Traditional Chinese Medicine

\section{Jiali Huang}

Chengdu University of Traditional Chinese Medicine

\section{Guo Xu}

Chengdu University of Traditional Chinese Medicine

\section{Qinxiu Zhang ( $\nabla$ zhqinxiu@163.com )}

Hospital of Chengdu University of Traditional Chinese Medicine,No.39 Shi-er-qiao

Road,Chengdu,Sichuan Province,P.R.China https://orcid.org/0000-0001-8746-0277

\section{Luyun Jiang}

Chengdu College of Traditional Chinese Medicine: Chengdu University of Traditional Chinese Medicine

\section{Research Article}

Keywords: Auricular acupressure, COVID-19, Vaccine, Adverse events, Randomized controlled trial, Protocol

Posted Date: October 29th, 2021

DOl: https://doi.org/10.21203/rs.3.rs-966861/v1

License: (c) (1) This work is licensed under a Creative Commons Attribution 4.0 International License. Read Full License

Version of Record: A version of this preprint was published at Trials on November 27th, 2021. See the published version at https://doi.org/10.1186/s13063-021-05837-x. 


\section{Abstract \\ Background}

Some pain, fatigue, and gastrointestinal adverse reactions were observed in potential association with injection of COVID-19 vaccines. However, there were no preventive intervention for it. We aim to investigate efficacy of auricular acupressure (AA) therapy in preventing and (or) relieving AEFI after injection of COVID-19 vaccine.

\section{Methods/design:}

The study design is a randomized controlled, multicentre, three-arm, single-blind trial. Participants meeting the inclusion criteria will be advertised and enrolled, and assigned randomly in the medical institutions for post-injection observation. No less than 360 participants will be randomized into one of three groups: auricular acupressure group, sham auricular acupressure group and wait-list group. Interventions will be performed immediately, and will happen 4 to 5 times per day for 5 days. The primary clinical outcomes will be quality and quantity evaluation among participants who reported any AEFI and who reported local pain at injection site. Secondary outcomes will concern headache, muscle and (or) joint pain, fatigue, nausea, vomiting, diarrhoea, and other potential events. All the outcomes will be assessed at baseline, 1, 3, 5, 7, and 14 days after the injection. Both intention-to-treat and per-protocol analyses will be performed, with significance level determined at the $5 \%$ level.

\section{Discussion}

Results of this trial will help clarify the value of auricular acupressure therapy in preventing and (or) relieving overall and certain adverse events following immunization after injection of COVID-19 vaccine.

\section{Trial registration:}

This trial was registered in the China Clinical Trial Registry (ChiCTR) (ChiCTR2100043210) on 8th February, 2021.

\section{Background}

As of October 5th, 2021, a total of 234 million people were confirmed infected with SARS-CoV-2, including 4.8 million deaths worldwide [1]. Developing immunity through COVID-19 vaccination provides a reduced risk of being infected and helps to fight the virus if exposed, which can save uncounted lives and give us a pathway out of the global disaster [2,3]. Researches showed that novel coronavirus-19 vaccines (NCV) were of considerable efficacy, and improvement on efficacy, especially long-term protection, and exploration of new species of vaccines are being conducted [4-8]. Some new variants of COVID-19 have 
been emerging, which may exacerbate COVID-19 symptoms, while researches reveal that many still with good immunogenicity $[9,10]$. However, some studies show concern on prevention efficacy in the situation $[11,12]$. For this, some researchers argue for strengthening injection of current NCV, simultaneously, new COVID-19 vaccines are being developed by countries $[13,14]$. According to the WHO, till October 5th, 2021, 124 of vaccine products are in clinical development, and 194 are in pre-clinical development worldwide, with the top three types of vaccines listed as protein subunit $(43,35 \%)$, viral vector (non-replicating, 18 , $15 \%)$ and DNA $(12,10 \%)[15]$.

Clinical experiments observed some adverse events following immunization (AEFI) in potential association with injection of COVID-19 vaccines, though most of them disappeared after several or a dozen days without special medical intervention. Among them, most frequent events were localized reactions (such as pain, sore, swelling, and itching), followed by fatigue, fever (some with chills), headache, myalgia, dizziness, and nausea (some with vomiting) [4-6, 16-19]. Mechanically, most AEFI are induced by hypersensitivity of organs or immune response to vaccine, which is more obvious in strengthening injection of NCV, especially [20,21].

Till now, no study has been made on preventive intervention for AEFI after injection of COVID-19 vaccines or on other vaccines. Considering the huge medical burden and potential hesitancy, anxiety or even rejection of some people toward COVID-19 vaccines injection, an appropriate preventive intervention is needed, which can provide better comfort and higher quality of lives in short terms both physiologically and psychologically [17-19, 22]. We published structured protocol summary of this study for brief introduction, with full Chinese protocol attached [23]. For months, some patients, researchers and people who were interested mailed us about more details of the protocol and study in English worldwide. As a result, we conduct a full-length protocol of the study.

Auricular acupressure (AA) therapy is non-invasive and non-pharmaceutical, easily taught and selfimplemented, inexpensive and with nearly no side effect. By pressing at auricular acupoints, the therapy can stimulate the meridians, influence the release of neurotransmitters that transmit signals along neurons, and regulate the function of endocrine and viscera [24,25]. Researches showed that AA has been successfully used for surgery pain, hypertension and insomnia, anxiety, and depression, and relieving nausea, vomiting, constipation, fatigue and lack of appetite related to chemotherapy [24-29]. Weighing up the harm-benefit balance, evidence suggests potential benefits of AA therapy on preventing and relieving vaccine-related $\mathrm{AEFI}$.

As a result, this study was designed to investigate dynamically whether AA therapy was effective in preventing and (or) relieving overall and certain AEFI of COVID-19 vaccine after injection compared with sham auricular acupressure (SAA) and wait-list (WL) control.

\section{Objectives}


To test whether AA therapy was effective in preventing and (or) relieving AEFI of the COVID-19 vaccine after injection compared with SAA and WL control.

\section{Materials And Methods}

\section{Study design}

This study will be a multicentre, three-arm (including AA group, SAA group, and WL group), single-blind, prospective randomized controlled trial, approved by the Ethics Committee of Hospital of Chengdu University of Traditional Chinese Medicine (2021KL-015), and jointly funded. No less than 360 participants for one type of NCV will be advertised and enrolled and randomly assigned to one of the three groups. To examine the effective of AA therapy in preventing and (or) relieving AEFI related to NCV, measurements will be taken once the injection is completed, and the participants will be followed after 1 , $3,5,7$, and 14 days after NCV injection. Participants will be asked to accept assessments at baseline. This randomized controlled clinical trial began recruitment on March $17^{\text {th }}, 2021$ and the anticipated completion date is February 2022. The primary outcome are quality and quantity evaluation among participants who reported any AEFI and who reported local pain at injection site. The flow chart of the trial is shown in Figure 1, and the participant timeline is listed in Table 1. Informed consent is obtained from each participant. The protocol is reported following the SPIRIT guidelines [30].

\section{Table 1: The participant timeline of our study}




\begin{tabular}{|c|c|c|c|c|c|c|c|c|}
\hline \multirow[t]{2}{*}{ Timepoints } & & \multirow{2}{*}{$\begin{array}{l}\text { Recruitment } \\
-\mathrm{T} 1\end{array}$} & \multirow{2}{*}{$\begin{array}{l}\text { Allocation } \\
0\end{array}$} & \multicolumn{5}{|c|}{ The first dose } \\
\hline & & & & $\mathrm{T} 1^{*}$ & $\mathrm{~T} 2 *$ & T3* & $\mathrm{T} 4^{\star}$ & $\mathrm{T} 5^{\star}$ \\
\hline \multirow[t]{4}{*}{ Entry items } & Inclusion / Exclusion & $x$ & & & & & & \\
\hline & Informed consent & $x$ & & & & & & \\
\hline & Randomization & & $x$ & & & & & \\
\hline & $\begin{array}{l}\text { Precautions for } \\
\text { distribution }\end{array}$ & & & $x$ & & & & \\
\hline \multirow[t]{3}{*}{ Interventions } & $\begin{array}{l}\text { Auricular point } \\
\text { acupressure }\end{array}$ & & & $\mathrm{x}-$ & & & & \\
\hline & $\begin{array}{l}\text { Sham auricular } \\
\text { point acupressure }\end{array}$ & & & $\mathrm{x}-$ & & & & \\
\hline & Wait-list control & & & Wait & ist cor & & & \\
\hline \multirow[t]{10}{*}{ Follow-ups } & $\begin{array}{l}\text { Baseline } \\
\text { characteristics }\end{array}$ & & $x$ & & & & & \\
\hline & $\begin{array}{l}\text { Local pain at } \\
\text { injection site\# }\end{array}$ & & & $x$ & $x$ & $x$ & $x$ & $x$ \\
\hline & Headache\# & & & $x$ & $x$ & $x$ & $x$ & $x$ \\
\hline & $\begin{array}{l}\text { Muscle and (or) joint } \\
\text { pain\# }\end{array}$ & & & $x$ & $x$ & $x$ & $x$ & $x$ \\
\hline & Fatigue\# & & & $x$ & $x$ & $x$ & $x$ & $x$ \\
\hline & Nausea\# & & & $x$ & $x$ & $x$ & $x$ & $x$ \\
\hline & Vomiting\# & & & $x$ & $x$ & $x$ & $x$ & $x$ \\
\hline & Diarrhoea\# & & & $x$ & $x$ & $x$ & $x$ & $x$ \\
\hline & $\begin{array}{l}\text { Other AEFI reported } \\
\text { by participants but } \\
\text { not listed above\# }\end{array}$ & & & $x$ & $x$ & $x$ & $x$ & $x$ \\
\hline & $\begin{array}{l}\text { Adverse events of } \\
\text { the interventions* }\end{array}$ & & & $x$ & $x$ & $x$ & $x$ & $x$ \\
\hline
\end{tabular}

Note: T1 : Immediately after the first or second dose of vaccine; T2 $*: 3$ days after the first or second dose of the vaccine; T3*: 5 days after the first or second dose of vaccine; T4*: 7 days after the first or second dose of vaccine; T5*: 14 days after the first or second dose of vaccine; \#: Record as cases with visual analog scale (VAS) scores from 0 to 10; Adverse events of the interventions *: including abnormal pain, skin allergy and other adverse reactions.

\section{Inclusion criteria}


Vaccinators will be screened strictly for meeting the criteria of the NCV injection shortly before the injection (during registration) [31]. Patients will be included if they meet all the following criteria:

1) Conforming to the conditions of the injection without contraindication, and completing the NCV injection within 24 hours before screening;

2) No headache, muscle or joint pain, fatigue, diarrhoea, nausea or vomiting experienced (no more than 4 scores, VAS) within three days before the injection, and no diseases (diagnosed) presenting the symptoms above;

3) No redness, swelling, injury or infection on the skin or soft tissue of bilateral ears;

4) No history of alcohol and adhesive tape contact allergy;

5) Able to complete the follow-up questionnaires independently online or by phone;

6) Agree to participate and sign the informed consent, and abide by precautions after the injection and requirements of $A A$ therapy.

In addition, it should be pointed out that due to the emergency of NCV injection and the good safety of AA therapy, we do not restrict ages and genders among participants. We will conduct sub-groups for different ages for comparison.

\section{Exclusion criteria}

Patients will be excluded if they have one or more of the following:

1) Not suitable to be vaccinated because of contraindication or were in cautious condition;

2) Have participated in other trials within 4 weeks before the start of this study;

3) With headache, muscle or joint pain, fatigue, diarrhoea, nausea or vomiting experienced (serious than 4 scores, VAS) within three days before the injection, or with diseases (diagnosed) presenting the symptoms above;

4) Pregnant or lactating women;

5) With other serious primary diseases and psychosis.

\section{Withdraw from the trial}

Participants will be allowed or asked to drop out from the trial if they:

1) Are lost to follow-up

2) Become pregnant 
3) Develop serious adverse event (SAE)

Participants can withdraw from this clinical trial at any time. The date and reason for withdrawal should be stated. If possible, all subjects withdrawing from the study should continue to be followed up regularly on a measurement schedule with a final assessment for intention-to-treat analysis.

\section{Recruitment}

We will recruit participants through leaflets and posters when waiting for the injection, and will be advertised, recruited during remaining in the medical institutions for post-injection observation (at less 30 mins). Trial investigators will examine respondents in the observation areas for eligibility screening. Informed consent will be obtained from eligible patients before randomization.

\section{Intervention}

All researchers received enough pre-experiment training, and acupuncturists who performed AA and SAA were trained for at least 4 years with clinical experience. Five auricular acupoints were applied for both AA and SAA groups, bilaterally, including Shenmen (TF4), Pi (Spleen, C013), Xin (Heart, C015), Pizhixia (Subcortex, AT4), Jiaogan (sympathetic, AH6a) for AA group, and Gangmen (Anus, HX5), Niaodao (Urethra, HX3), Helix 1 (HX9), Helix 2 (HX10), Helix 3 (HX11) for SAA group (Figure 2 and Table 2).

Table 2: Auricular acupoints selected in our protocol (with location and function) 


\begin{tabular}{|c|c|c|c|}
\hline Group & $\begin{array}{l}\text { Auricular } \\
\text { acupoints }\end{array}$ & Anatomical location & $\begin{array}{l}\text { Main function(s) according } \\
\text { to TCM }\end{array}$ \\
\hline \multirow[t]{5}{*}{$\begin{array}{l}\text { For the } \\
\text { auricular } \\
\text { acupressure } \\
\text { group }\end{array}$} & $\begin{array}{l}\text { Shenmen } \\
\text { (TF4) }\end{array}$ & $\begin{array}{l}\text { The upper part of the posterior } 1 / 3 \\
\text { of the triangular fossa of auricle } \\
\text { (Area } 4 \text { of auricle triangular fossa) }\end{array}$ & $\begin{array}{l}\text { Insomnia, abnormal } \\
\text { sweating, pain, cough, } \\
\text { asthma, vertigo, } \\
\text { hypertension, allergy, } \\
\text { Withdrawal Syndrome, } \\
\text { epilepsy }\end{array}$ \\
\hline & $\begin{array}{l}\text { Pi (Spleen, } \\
\text { c013) }\end{array}$ & $\begin{array}{l}\text { Below the BD line of the auricle and } \\
\text { above the posterior part of the } \\
\text { concha cavity (Concha } 13 \text { area of } \\
\text { auricle) }\end{array}$ & $\begin{array}{l}\text { Diarrhea, abdominal } \\
\text { distention, constipation, loss } \\
\text { of appetite, functional } \\
\text { uterine bleeding, excessive } \\
\text { leucorrhea, inner ear vertigo, } \\
\text { edema, visceral ptosis }\end{array}$ \\
\hline & $\begin{array}{l}\text { Xin (Heart, } \\
\text { C015) }\end{array}$ & $\begin{array}{l}\text { In the middle of the concha cavity of } \\
\text { the auricle (Concha } 15 \text { area of } \\
\text { auricle) }\end{array}$ & $\begin{array}{l}\text { Tachycardia, arrhythmia, } \\
\text { angina pectoris, } \\
\text { spontaneous sweating, night } \\
\text { sweats, hysteria, sore tongue, } \\
\text { palpitation, insomnia, } \\
\text { forgetfulness }\end{array}$ \\
\hline & $\begin{array}{l}\text { Pizhixia } \\
\text { (Subcortex, } \\
\text { AT4) }\end{array}$ & $\begin{array}{l}\text { On the inner side of the opposite } \\
\text { tragus of the auricle (Zone } 4 \text { of the } \\
\text { opposite tragus of the auricle) }\end{array}$ & $\begin{array}{l}\text { Pain, neurasthenia, gastric } \\
\text { ulcer, pseudomyopia, } \\
\text { diarrhea, hypertension, } \\
\text { coronary heart disease, } \\
\text { arrhythmia, insomnia }\end{array}$ \\
\hline & $\begin{array}{l}\text { Jiaogan } \\
\text { (sympathetic, } \\
\text { AH6a) }\end{array}$ & $\begin{array}{l}\text { At the junction of the anterior } \\
\text { segment of the lower foot of the } \\
\text { opposite ear wheel of the auricle } \\
\text { and the inner edge of the ear wheel } \\
\text { (Anterior segment of zone } 6 \text { of the } \\
\text { opposite ear wheel) }\end{array}$ & $\begin{array}{l}\text { Autonomic nervous function } \\
\text { diseases, visceral pain }\end{array}$ \\
\hline \multirow{5}{*}{$\begin{array}{l}\text { For the } \\
\text { sham } \\
\text { auricular } \\
\text { acupressure } \\
\text { group }\end{array}$} & $\begin{array}{l}\text { Gangmen } \\
\text { (Anus, HX5) }\end{array}$ & $\begin{array}{l}\text { In front of the triangular fossa of the } \\
\text { auricle (Ear wheel area } 5 \text { of the } \\
\text { auricle) }\end{array}$ & Hemorrhoids, anal fissure \\
\hline & $\begin{array}{l}\text { Niaodao } \\
\text { (Urethra, } \\
\text { HX3) }\end{array}$ & $\begin{array}{l}\text { At the anterior and upper part of the } \\
\text { protrusion of the foot of the auricle } \\
\text { (Ear wheel area } 3 \text { of the auricle) }\end{array}$ & $\begin{array}{l}\text { Frequent urination, urgent } \\
\text { urination, urinary pain, } \\
\text { urinary retention }\end{array}$ \\
\hline & Helix 1 (HX9) & $\begin{array}{l}\text { Below the tubercle of the auricle (Ear } \\
\text { wheel area } 9 \text { of the auricle) }\end{array}$ & \multirow[t]{3}{*}{$\begin{array}{l}\text { Tonsillitis, upper respiratory } \\
\text { tract infection, fever }\end{array}$} \\
\hline & $\begin{array}{l}\text { Helix } 2 \\
\text { (HX10) }\end{array}$ & $\begin{array}{l}\text { Just below the Helix } 1 / \mathrm{HX} 9 \text { (Ear } \\
\text { wheel area } 10 \text { of the auricle) }\end{array}$ & \\
\hline & $\begin{array}{l}\text { Helix } 3 \\
\text { (HX11) }\end{array}$ & $\begin{array}{l}\text { Just below the Helix } 2 / \mathrm{HX} 10 \text { (Ear } \\
\text { wheel area } 11 \text { of the auricle) }\end{array}$ & \\
\hline
\end{tabular}


Auricular acupoints for AA group and SAA group were selected according to relevant international and national standards of China, expert consultation, our experience, and based on potential AEFI of the vaccines from previous studies [4-6,16-19,32-34]. Tools (model "Ziyu"; He's Medical Device Co., Ltd, Henshui, China) applied for AA and SAA were Semen Vaccariae (about $2 \mathrm{~mm}$ in diameter), which were black, round, hard and very small without special smell, covered with small tapes (about $0.8 \times 0.8 \mathrm{~mm} 2$ ) (Figure 3).

Surface of the auricular acupoints, marked on stick figures with two protocols associated with the sequence numbers for AA and SAA, was cleaned and dried with disinfection swabs, and Semen Vaccariae tapes were pasted in the acupoints by the acupuncturists and pressed with fingers to achieve sensation of soreness or distention.

In addition, the participants in AA and SAA groups were informed to press the tapes by themselves for 1 minute vertically and appropriately to achieve the sensation, with a duration of 4 to 5 times a day and 5 days in total. The content above was written in Attention After AA Therapy, which were distributed to the participants with the individual sequence number recorded.

All of these were free for the participants, and they were informed at the beginning of the trial that two sessions of AA therapy, based on individual health condition, would be provided for free upon accomplishment of the study.

\section{Outcomes}

All outcomes will be accessed and evaluated from the participants online or by phone in 1, 3, 5, 7, and 14 days after NCV injection, which they thought might be related to the injection. Primary outcomes are percentages of participants who reported any AEFI and who reported local pain at injection site, with their severity evaluated by visual analog scale (VAS) scores of $0-10$. Secondary outcomes include

percentages of participants who reported headache, muscle and (or) joint pain, fatigue, nausea, vomiting and diarrhoea, together with other AEFI reported by participants but not listed above, and with their severity evaluated by the VAS scores, similarly. In addition, AEFI with extra specific medical intervention will be recorded. Adverse events associate with the AA therapy for AA and SAA groups will also be recorded, with cases, severity, measurement and outcomes. Follow-ups will be performed by blinded evaluators.

Due to the large number of vaccinations in facilities, especially in the waiting and observation areas, timeconsuming questionnaires and indicators with more complexity will not be implemented.

\section{Assignment and blinding}

After confirmation for eligibility and collection of written informed consents, participants will be randomized through a random allocation software (The Hefei Big Orange Software Technology Co., Ltd, V 2.1.8), and be allocated to the AA, SAA, and WL groups in a 1:1:1 ratio with stratifying by centres. Sequentially numbered sequences with combination of numbers and letters will be performed and 
recorded by registrars to conceal the random sequence for the participants, outcome assessors and statisticians. The sequences will be generated and concealed by trained research assistants. The participants in the AA group and SAA group, and outcome assessors, statisticians will be blinded, while participants in the WL group and the acupuncturists will not.

\section{Sample size calculation}

No less than 360 participants will be randomized in 1:1:1 ratio to each group. This is a protocol for an explorative study, therefore, a formal sample size is unavailable and not calculated.

\section{Statistical analysis}

Clinical outcomes will be analysed in both intention-to-treat (ITT) and per-protocol (PP) participants, and missing values will be imputed by the last-observation-carried forward method. Results of participants who received AA, SAA or WL observation, and with baseline details recorded will be processed with ITT analyses, while those who complete all the 14-day evaluation and with the interventions applied correctly will be analysed with PP sets.

Descriptive analyses will be made of frequencies and percentages for the qualitative variables, and overall $p$ values will be estimated by $\chi 2$ or fisher $\chi 2$ test as appropriate with the Bonferroni approach. Pairwise comparisons will be performed as differences of percentages (DP), with $95 \% \mathrm{Cls}$ of the differences calculated by R (V4.0.1). Estimations for $p$ values of the pairwise comparisons will be performed by $\chi 2$, continuous or fisher $\chi 2$ test as appropriate in SPSS (V23.0). Two-tailed tests with $p<$ 0.05 define statistically significant for all analyses.

\section{Discussion And Conclusion}

The study is a multicentre, single-blinded, three-arm, randomized clinical trial with to evaluate the efficacy and safety of AA therapy in preventing and (or) relieving overall and certain AEFI of NCV compared with SAA and WL control. Some AEFI were observed in potential association with injection of NCV, while there is no preventive intervention for it. As a result, it would be the first of such research.

In traditional Chinese medicine, all the twelve meridians pass through the ear, and AA therapy promotes the circulation of Qi and blood, regulates the balance of Yin and Yang and the functions of the viscera [32]. If the outcome from this study favours AA therapy with good preventing and (or) relieving effects in AEFI of NCV, larger scale of studies may be proposed. Furtherly, AA therapy may also have the potential to be applied for preventing or relieving AEFI of other types of vaccine, and more researches is needed. In addition, AA therapy is self-implementable, and is also beneficial for relieving anxiety associated with the $\mathrm{AEFI}$, especially during the pandemic.

Main limitation of this study is that there are some risks that small number of participants may know certain effects of different auricular points when communicating with others, or when visiting a doctor. These may decrease the reliability of blinding methods and credible level of the study. In addition, 
blinding for the acupuncturists may not applicable due to their expertise. For this, we will record it if a participant has revived AA therapy for other discomforts, and encourage participants do not to communicate with others about the vaccariae tapes pasted on their auricular points.

In conclusion, this study is an explorative study and will firstly provide the basis for the effectiveness and safety of AA therapy on AEFI related to NCV injection, and would explore the possibility of AA therapy in the management of $A E F I$ related to injection of other vaccines.

\section{Trial Status}

The participants are currently being recruited for the present study.

\section{Abbreviations}

NCV

Novel coronavirus-19 vaccine

AEFI

Adverse events following immunization

AA

Auricular acupressure

SAA

Sham auricular acupressure

WL

wait-list

\section{Declarations}

\section{Ethics approval and consent to participate}

Approved by the Medical Ethics Committee of Hospital of Chengdu University of Traditional Chinese Medicine, Chengdu, China on February 2, 2021 with certificate No. 2021 KL-015. Before inclusion in the study, participants will be informed of the purpose of the study and of the clinical procedures required by the protocol. The investigators in each hospital will explain the purpose, risks and benefits associated with study participation. In addition, participants will be informed of their right to withdraw from the study at any time without explanation and without losing the right to future medical care. Every participant is free to leave the study protocol at any stage of the study, may withdraw his or her consent, and may request that all of his or her data be eliminated from the database.

\section{Consent for publication}

No baseline or pilot data is included in this study protocol. Figure 3 shows distribution of the auricular acupoints selected in our study on the surface of auricle, and it was approved by one of our authors 
(Zhiqiao Wang, whose auricle is showed in the Figure 3) with informed consent signed.

\section{Availability of data and materials}

The datasets used and analyzed during the current study are available from the corresponding author on reasonable request.

\section{Competing interests}

The authors declare that they have no competing interests.

\section{Funding}

This study is jointly supported by fundings from 1. Scientific Project of Hospital of Chengdu University of Traditional Chinese Medicine (No. 21LL2X03); 2. Chengdu Medical Research Project (2021002); 3. National College Students' Innovation and Entrepreneurship Project (202110633016); 4. Graduate Scientific Research Innovation Project of Clinical Medical College of Chengdu University of Traditional Chinese Medicine (2020ZS204).

\section{Authors' contributions}

Q. F., H. X., L. Z., X. L., Y. L., M. L., Q. Z. and L. J. were involved in the design of this trial. C. W., X. W., Z. W., Z. X., H. L., L. W. and C. S. will be involved in enrolment and randomization. J. T., H. X., J. Z., C. F., X. C. and X. W. to provide interventions, and C. W., X. W., Z. W., Z. A., Z. X., H. L., L. W. and C. S. to collect follow-up outcomes. Q. F., X. L., Y. L. and J., H. participates as statisticians, and Q. F., H. X., L. Z., Q. Z., L. J., G. X., S. $\mathrm{H}$. participates in drafting the work or revising it critically for intellectual content. All authors have read and approved the final structured summary.

\section{References}

1. World Health Organization. Weekly epidemiological update on COVID-19 - 5 October 2021. October 05. 2021. https://www.who.int/publications/m/item/weekly-epidemiological-update-on-covid-19--5october-2021.

2. Rubin EJ, Longo DL. SARS-CoV-2 Vaccination - An Ounce (Actually, Much Less) of Prevention. N Engl J Med. 2020;383(27):2677-8. doi:10.1056/NEJMe2034717.

3. Center for Disease Control and Prevention(CDC). Vaccines for COVID-19. October 05. 2021. https://www.cdc.gov/coronavirus/2019-ncov/vaccines/index.html.

4. Zhang Y, Zeng G, Pan H,et al. Safety, tolerability, and immunogenicity of an inactivated SARS-CoV-2 vaccine in healthy adults aged 18-59 years: a randomised, double-blind, placebo-controlled, phase 1/2 clinical trial. Lancet Infect Dis. 2021 Feb;21(2):181-192. doi: 10.1016/S1473-3099(20)30843-4.

5. Xia S, Duan K, Zhang Y,et al. Effect of an Inactivated Vaccine Against SARS-CoV-2 on Safety and Immunogenicity Outcomes: Interim Analysis of 2 Randomized Clinical Trials. JAMA. 2020 Sep 
8;324(10):951-960. doi: 10.1001/jama.2020.15543.

6. Baden LR, El Sahly HM, Essink B,et al. Efficacy and Safety of the mRNA-1273 SARS-CoV-2 Vaccine. N Engl J Med. 2021 Feb;4(5):403-16. doi:10.1056/NEJMoa2035389. 384 ) .

7. Vasileiou E, Simpson CR, Shi T,et al. Interim findings from first-dose mass COVID-19 vaccination rollout and COVID-19 hospital admissions in Scotland: a national prospective cohort study. Lancet. 2021 Apr 23;397(10285):1646-57. doi: 10.1016/S0140-6736(21)00677-2.

8. Collier DA, De Marco A, Ferreira IATM,et al. Sensitivity of SARS-CoV-2 B.1.1.7 to mRNA vaccineelicited antibodies. Nature. 2021 Mar 11. doi:10.1038/s41586-021-03412-7.

9. Liu Y, Liu J, Xia H, et al. Neutralizing Activity of BNT162b2-Elicited Serum. N Engl J Med. 2021;384(15):1466-8. doi:10.1056/NEJMc2102017.

10. Choi A, Koch M, Wu K, et al. Safety and immunogenicity of SARS-CoV-2 variant mRNA vaccine boosters in healthy adults: an interim analysis [published online ahead of print, 2021 Sep 15]. Nat Med. 2021. 10.1038/s41591-021-01527-y. doi:10.1038/s41591-021-01527-y.

11. Levin EG, Lustig Y, Cohen C, et al. Waning Immune Humoral Response to BNT162b2 Covid-19 Vaccine over 6 Months [published online ahead of print, 2021 Oct 6]. N Engl J Med. 2021. 10.1056/NEJMoa2114583. doi:10.1056/NEJMoa2114583.

12. Chemaitelly H, Tang P, Hasan MR, et al. Waning of BNT162b2 Vaccine Protection against SARS-CoV2 Infection in Qatar [published online ahead of print, 2021 Oct 6]. N Engl J Med. 2021.

10.1056/NEJMoa2114114. doi:10.1056/NEJMoa2114114.

13. Li XN, Huang Y, Wang W, et al. Effectiveness of inactivated SARS-CoV-2 vaccines against the Delta variant infection in Guangzhou: a test-negative case-control real-world study. Emerg Microbes Infect. 2021;10(1):1751-9. doi:10.1080/22221751.2021.1969291.

14. Tartof SY, Slezak JM, Fischer H, et al. Effectiveness of mRNA BNT162b2 COVID-19 vaccine up to 6 months in a large integrated health system in the USA: a retrospective cohort study [published online ahead of print, 2021 Oct 4]. Lancet. 2021;S0140-6736(21):02183-8. doi:10.1016/S01406736(21)02183-8.

15. World Health Organization. COVID-19 vaccine tracker and landscape. October 05, 2021. https://www.who.int/publications/m/item/draft-landscape-of-covid-19-candidate-vaccines.

16. Center for Disease Control and Prevention(CDC). Pfizer-BioNTech COVID-19 Vaccine Overview and Safety (also known as COMIRNATY). October 05, 2021. https://www.cdc.gov/coronavirus/2019ncov/vaccines/different-vaccines/Pfizer-BioNTech.html.

17. Lazarus JV, Ratzan SC, Palayew A,et al. A global survey of potential acceptance of a COVID-19 vaccine. Nat Med. 2021 Feb;27(2):225-8. doi:10.1038/s41591-020-1124-9.

18. Kwok KO, Li KK, Wei WI,et al. Editor's Choice: Influenza vaccine uptake, COVID-19 vaccination intention and vaccine hesitancy among nurses: A survey. Int J Nurs Stud. 2021 Feb;114:103854. doi: 10.1016/j.jinurstu.2020.103854.

19. Detoc M, Bruel S, Frappe P,et al. Intention to participate in a COVID-19 vaccine clinical trial and to get vaccinated against COVID-19 in France during the pandemic. Vaccine. 2020 Oct 21;38(45):7002- 
7006. doi: 10.1016/j.vaccine.2020.09.041.

20. He Q, Mao Q, Zhang J,et al. COVID-19 Vaccines: Current Understanding on Immunogenicity, Safety, and Further Considerations. Front Immunol. 2021 Apr 12;12:669339. doi: 10.3389/fimmu.2021.669339.

21. Center for Disease Control and Prevention(CDC). Safety Monitoring of an Additional Dose of COVID19 Vaccine - United States, August 12-September 19, 2021. October 05, 2021.

https://www.cdc.gov/mmwr/volumes/70/wr/mm7039e4.htm?s_cid=mm7039e4_w.

22. Mathioudakis AG, Ghrew M, Ustianowski A,et al. Self-Reported Real-World Safety and Reactogenicity of COVID-19 Vaccines: A Vaccine Recipient Survey. Life (Basel). 2021 Mar 17;11(3):249. doi: 10.3390/life11030249.

23. Fu Q, Xie H, Zhou L, et al. Traditional Chinese medicine auricular point acupressure for the relief of pain, fatigue, and gastrointestinal adverse reactions after the injection of novel coronavirus- 19 vaccines: a structured summary of a study protocol for a multicentre, three-arm, single-blind, prospective randomized controlled trial. Trials. 2021;22(1):162. doi:10.1186/s13063-021-05138-3. Published 2021 Feb 25.

24. Eghbali M, Yekaninejad MS, Varaei S,et al. The effect of auricular acupressure on nausea and vomiting caused by chemotherapy among breast cancer participants. Complement Ther Clin Pract. 2016 Aug;24:189-94. doi:10.1016/j.ctcp.2016.06.006.

25. Shin J, Park H. Effects of Auricular Acupressure on Constipation in participants With Breast Cancer Receiving Chemotherapy: A Randomized Control Trial. West J Nurs Res. 2018 Jan;40(1):67-83. doi: $10.1177 / 0193945916680362$.

26. Lin L, Zhang Y, Qian HY,et al. Auricular acupressure for cancer-related fatigue during lung cancer chemotherapy: a randomised trial. BMJ Support Palliat Care. 2021 Mar;11(1):32-9. doi:10.1136/bmjspcare-2019-001937.

27. Yeh ML, Tsou MY, Lee BY,et al. Effects of auricular acupressure on pain reduction in participantcontrolled analgesia after lumbar spine surgery. Acta Anaesthesiol Taiwan. 2010 Jun;48(2):80-6. doi:10.1016/S1875-4597(10)60018-5.

28. Zhao ZH, Zhou Y, Li WH,et al. Auricular Acupressure in participants with Hypertension and Insomnia: A Systematic Review and Meta-Analysis. Evid Based Complement Alternat Med. 2020 Jun 17;2020:7279486. doi: 10.1155/2020/7279486.

29. Chueh KH, Chang CC, Yeh ML. Effects of Auricular Acupressure on Sleep Quality, Anxiety, and Depressed Mood in RN-BSN Students With Sleep Disturbance. J Nurs Res. 2018 Feb;26(1):10-17. doi: 10.1097/JNR.0000000000000209.

30. Chan A-W, Tetzlaff JM, Gøtzsche PC, Altman DG, Mann H, Berlin J, Dickersin K, Hróbjartsson A, Schulz KF, Parulekar WR, Krleža-Jerić K, Laupacis A, Moher D. SPIRIT 2013 Explanation and Elaboration: Guidance for protocols of clinical trials. BMJ. 2013;346:e7586.

31. National Health Commission of the People's Republic of China. Guideline for Thchniques of COVID19 Vaccine Injection(First Edition). March 29, 2021. https://zwfw.nhc.gov.cn/kzx/zcfg/zcfgqb/. 
32. Huang LC. Auricular medicine: a complete manual of auricular diagnosis and treatment. 1st ed. Orlando: Auricular International Research \& Training; 2005.

33. Zhang Y, Huang Y, Li H,et al. Transcutaneous auricular vagus nerve stimulation (taVNS) for migraine: an fMRI study. Reg Anesth Pain Med. 2021 Feb;46(2):145-50. doi:10.1136/rapm-2020-102088.

34. Zhou L, Zhao B. National Technical Committee on Acupuncture and Moxibustion of Standardization Administration of China. Nomenclature and location of auricular points, GB/T 13734-2008. National Administration of Traditional Chinese Medicine of China, 2008-04-23.

(http://c.gb688.cn/bzgk/gb/showGb?type=online\&hcno=D6A125ED4011A9A625F8A3ACE425EE09).

\section{Figures}




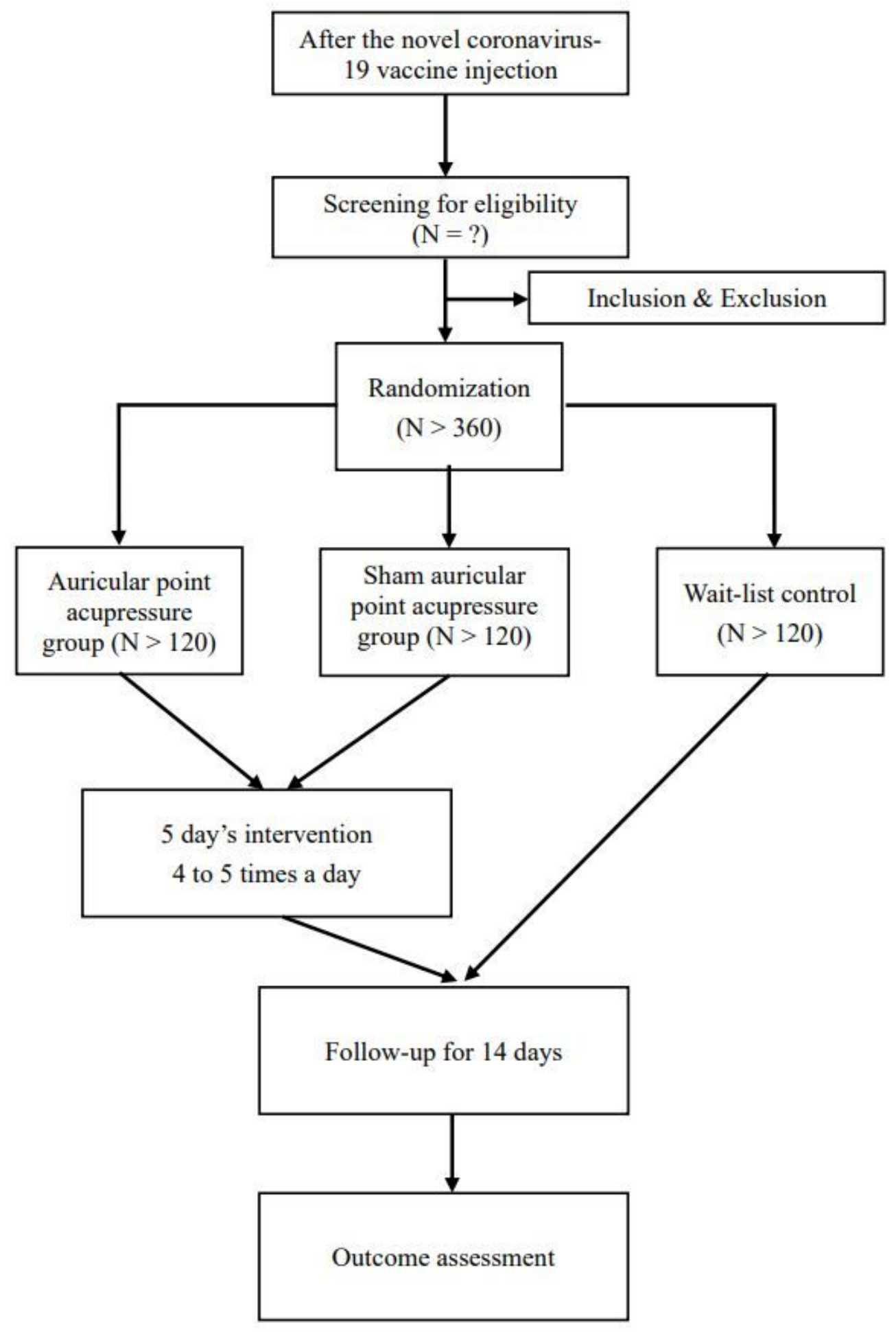

Figure 1

The flow chart of the trial 

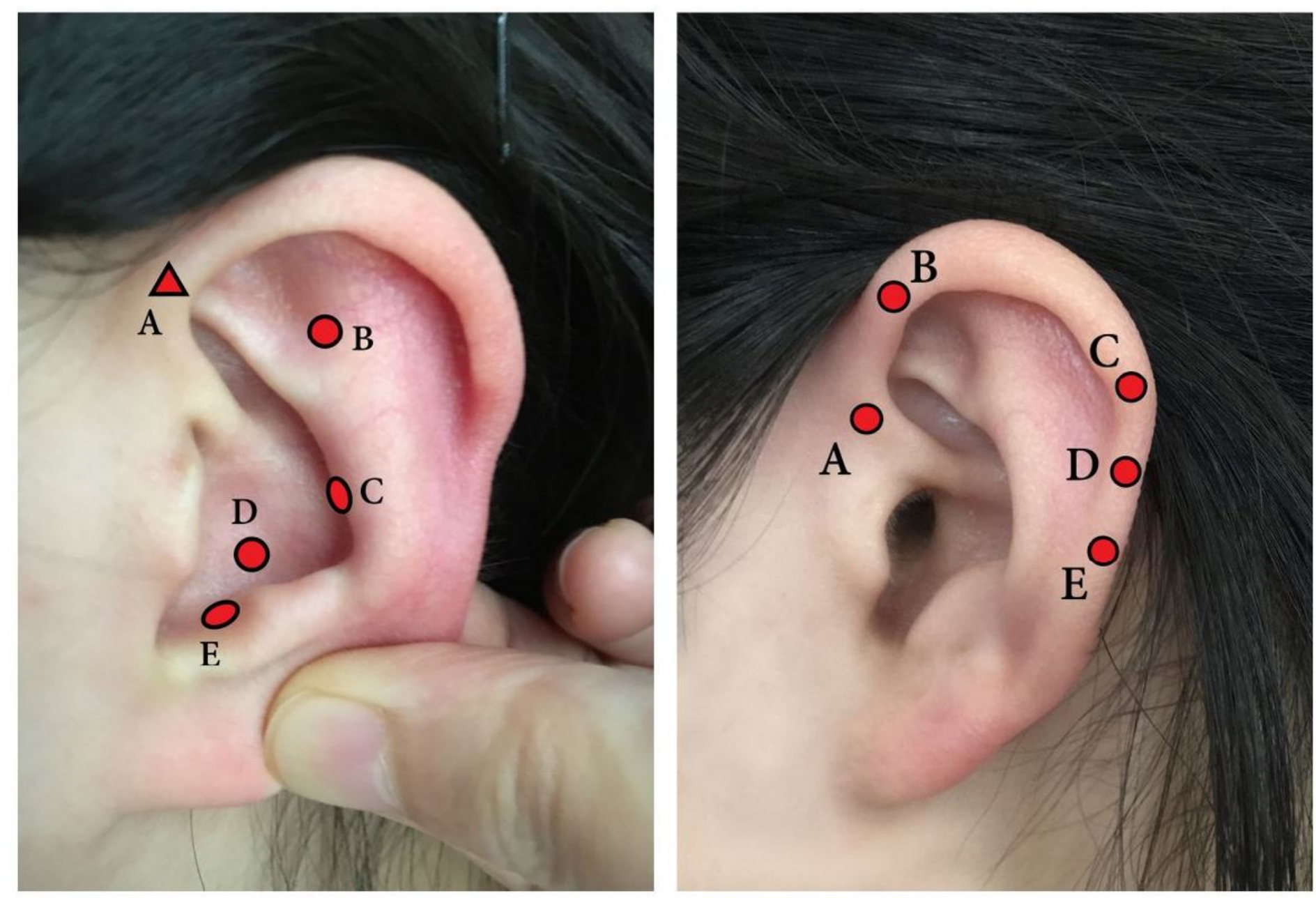

\section{Figure 2}

Auricular acupoints applied for AA and SAA groups Circular marks indicate the acupoints are located at the outer surface, and triangle mark indicates the acupoint is at inside surface. The left picture is the distribution of auricular acupoints applied for AA group, including A [Jiaogan (sympathetic, AH6a)], B [Shenmen (TF4)], C [Pi (Spleen, C013)], D [Xin (Heart, C015)], E [Pizhixia (Subcortex, AT4)]. The picture in the right is the distribution of auricular acupoints applied for SAA group, including $A$ [Niaodao (Urethra, HX3)], B [Gangmen (Anus, HX5)], C [Helix 1 (HX9)], D [Helix 2 (HX10)], E [Helix 3 (HX11)]. 


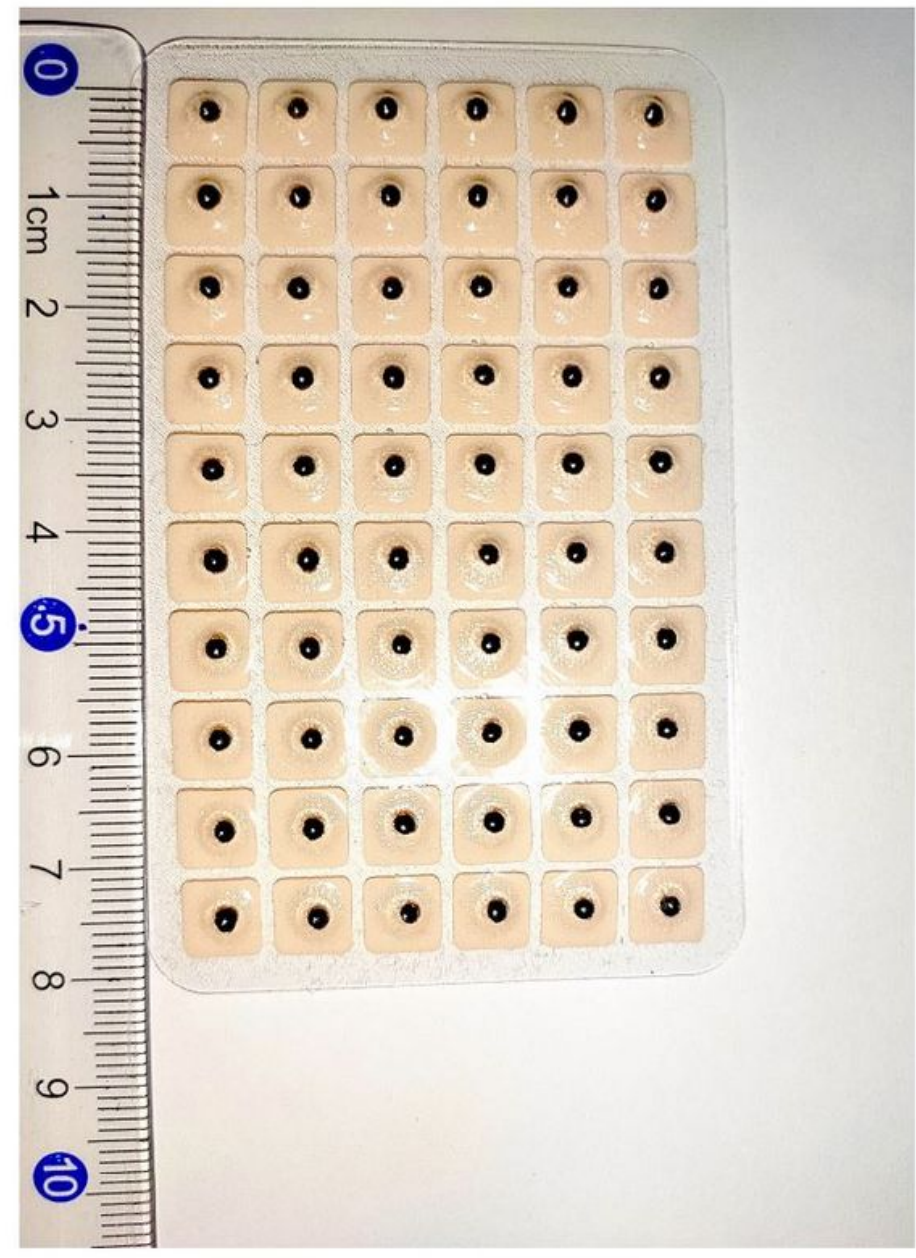

Figure 3

The Consolidated Standards for Reporting Trials diagram of the study AA: Auricular acupressure; SAA: Sham auricular acupressure; WL: wait-list. The Semen Vaccariae tapes in our study 